\title{
Biocombustível renovável: uso de óleo vegetal em motores
}

\author{
Renewable biofuel: use of vegetable oil in engines
}

\author{
Edson Perez Guerra ${ }^{[a]}$, Werner Fuchs ${ }^{[\mathrm{b}]}$ \\ ${ }^{[a]}$ Engenheiro agrônomo, Doutor, professor adjunto da Pontifícia Universidade Católica do Paraná (PUCPR), São José dos Pinhais, \\ PR - Brasil, e-mail: e.guerra@pucpr.br \\ ${ }^{[b]}$ Pastor, coordenador do Programa de Mini-usinas de Extração de Óleo Vegetal a Frio, da Cooperativa Produção Industrial e \\ Comércio de Mini-Usinas Compacta (Cooperbiobrasil), Curitiba, PR - Brasil, e-mail: w.fuchs@uol.br
}

\section{Resumo}

O óleo vegetal extraído de sementes de plantas e utilizado como fonte de energia renovável é uma alternativa ambientalmente correta e sustentável. O objetivo deste trabalho foi apresentar técnicas e experiências atuais de uso de óleo vegetal em motores de ciclo diesel. Várias experiências de uso de óleo vegetal em motores têm apresentado benefícios, tais como economia de custo de produção, equivalência no desempenho dos veículos, adequação a diferentes motores em mistura com diesel ou uso de óleo vegetal puro com adaptação do equipamento, diversidade de fontes vegetais para obtenção do óleo e aproveitamento de coprodutos, sem poluição do ambiente, dentre outros. O uso de óleo vegetal como biocombustível é uma realidade, com milhares de veículos circulando em vários países, e que tende a aumentar com a conscientização da população e interesse de empresas e governos.

Palavras-chave: Extração a frio. Injeção eletrônica. Energia alternativa.

\begin{abstract}
The vegetable oil extracted from plant seeds and used as source of renewable energy is a correct alternative and environmentally sustainable. The aim of this paper is to present techniques and experiences of current use of vegetable oil in diesel engines. Several experiments using vegetable oil in engines have shown reduction of the cost production, equivalence in vehicle performance, suitability to different engines by blending with diesel or using pure vegetable oil with adaptation of the equipment, variety of plant sources for obtaining oil and utilization of co-products, without environmental pollution, among other benefits. The use of vegetable oil as biofuel is a reality, with thousands of vehicles circulating in several countries, and it tends to increase with population awareness and interest of companies and governments.
\end{abstract}

Keywords: Cold extraction. Electronic injection. Alternative energy. 


\section{Introdução}

Em decorrência da crise energética mundial, intensifica-se a procura por alternativas ambientalmente corretas e sustentáveis. Dentre os combustíveis biológicos renováveis usados atualmente, destacam-se o álcool, o biodiesel, o biogás e o óleo vegetal. O uso de óleo vegetal como combustível é uma alternativa abundante e renovável, extraído de uma grande diversidade de espécies (FUCHS, 2006).

A demanda por combustíveis renováveis está se expandindo rapidamente nos últimos anos. Considera-se uma fonte alternativa renovável qualquer fonte de energia capaz de se regenerar dentro do ciclo de vida de sua utilização e que possa ser utilizada pelas gerações futuras. As fontes mais conhecidas são a eólica, a biomassa, a solar (térmica, fotovoltaica e heliotérmica), a energia dos oceanos (marés, ondas, correntes oceânicas e gradiente térmico) e a hídrica de pequeno porte. A biomassa para a matriz energética brasileira é toda matéria orgânica que possa ser transformada em energia mecânica, térmica ou elétrica (MELO, 2009).

Com as sucessivas crises mundiais do petróleo, foi necessário voltar a atenção para outras fontes de energia. O óleo vegetal tornou-se uma das mais importantes opções, reconhecida principalmente na Europa. Desde 2003, na União Europeia os óleos vegetais são biocombustíveis reconhecidos e regulamentados, sendo amplamente utilizados em caminhões, ônibus, picapes, tratores, carros de passeio, barcos e geradores.

O primeiro motor inventado por Rudolf Diesel, em 1893, utilizava óleo de amendoim. Na década de 1910, a indústria direcionou trabalhos de desenvolvimento do motor para utilização com diesel, o óleo cru do petróleo.

O Brasil possui um grande potencial de produção de óleo vegetal, capaz de alimentar boa parte da população mundial e de produzir energia. O óleo pode ser extraído de diversas espécies de plantas que crescem em diferentes condições ambientais. A diversidade de plantas oleaginosas é enorme, representadas por espécies como: dendê, macaúba, babaçu, tucum, coco, buriti, noz pecã, castanha, macadâmia, pinhão, amendoim, soja, canola, nabo forrageiro, pinhão-manso, tungue, girassol, algodão, linhaça, gergelim, crambe, cártamo, nim e moringa, dentre muitas outras (GUERRA; FUCHS, 2009b).

A produção de óleo vegetal pode ser feita tanto por grandes como pequenos produtores, possibilitando a descentralização. Dominando todo o processo de extração de óleo, os agricultores poderão obter outros produtos associados ou coprodutos, de alto valor nutricional e comercial, como a torta, a farinha, o gérmen de soja, dentre outros.

O objetivo deste trabalho é apresentar técnicas e experiências atuais de uso de óleo vegetal em motores de ciclo diesel.

\section{Desenvolvimento}

Quando Rudolf Diesel inventou o motor a combustão interna (motor diesel) no fim do século XIX, utilizou em seus ensaios o petróleo e o óleo de amendoim como combustíveis. Esse foi o início do uso de óleo vegetal como combustível. Em 1900, durante a exposição internacional em Paris, Rudolph Diesel testou o óleo de amendoim e outros óleos vegetais, a pedido do governo francês, e percebeu que o motor funcionava perfeitamente. $\mathrm{Na}$ época, porém, o petróleo era barato e acabou sendo preferido como combustível para esses motores. Apesar desse fato, na primeira metade do século XX esporadicamente os óleos vegetais puros foram usados nos motores do ciclo diesel, quando ocorreram crises no abastecimento mundial de petróleo, como na época da Segunda Guerra Mundial (FUCHS, 2006; FUCHS, 2007).

Com o passar do tempo, tanto o motor quanto o combustível foram sendo melhorados. Assim, os óleos vegetais não puderam mais ser usados puros como combustíveis, pois sua densidade e viscosidade são muito altas em relação ao óleo diesel, provocando problemas de injeção do combustível no motor e também uma queima incompleta, levando à formação de coque nos motores, os quais podem sofrer sérios danos em médio e longo prazo. Dessa forma, o óleo vegetal deve ser usado misturado com o diesel de petróleo, ou deverá ser feita uma adaptação no motor para que seja usado 100\% de óleo (FUCHS, 2006; GUERRA; FUCHS, 2009a). 
Na segunda metade do século XX ocorreram crises no mercado mundial de petróleo, especificamente nas décadas de 70 e 90 . A demanda por energia aumentou, assim como a consciência ambiental da população. Esses fatores conduziram a um movimento no sentido da produção de combustíveis alternativos provenientes de fontes renováveis. Os biocombustíveis passaram a ter papel de destaque nesse cenário (FUCHS, 2006; GUERRA; FUCHS, 2009a).

\section{Uso de biocombustíveis}

No início da década de 1990, na Europa, principalmente na Alemanha, França e Áustria, ésteres derivados de óleos vegetais começaram a ser usados em escala comercial como combustível, com o nome de biodiesel. Outros países, tais como Estados Unidos, Canadá, Malásia e Argentina, também se dedicaram ao desenvolvimento de tecnologias viáveis para a produção de combustíveis a partir de óleos vegetais. No mercado internacional, o biodiesel produzido tem sido utilizado em veículos de passeio, frotas cativas, transporte público e geração de eletricidade (FUCHS, 2006; GUERRA; FUCHS, 2009a).

Paralelamente, cresce o uso do óleo vegetal como combustível. Na Alemanha há cerca de 100 mil veículos movidos a óleo vegetal, incluindo navios, caminhões, ônibus, tratores e automóveis. O consumo de agrocombustíveis líquidos na Alemanha em 2006 foi avaliado em: 61\% biodiesel, 27\% OV direto e 12\% etanol. As empresas John Deere e Deutz-Fahr lançaram tratores movidos a óleo vegetal na Europa. Na Rússia há motocicletas movidas a esse tipo de combustível. Estão em andamento na Nova Zelândia e Japão testes com óleo vegetal de pinhão-manso em turbinas de aeronaves Boeing 747 (FUCHS, 2008; FUCHS, 2009).

O uso energético de óleos vegetais no Brasil esteve sempre presente nas discussões envolvendo a diversificação dos combustíveis líquidos. No início da década de 1940, foram realizados estudos no sentido de usar óleos vegetais in natura ou hidrocarbonetos obtidos pelo seu craqueamento como combustíveis alternativos ao óleo diesel. Durante a Segunda Guerra Mundial, o governo brasileiro, por decreto, proibiu a exportação de óleo de algodão, para forçar a queda do preço desse óleo no mercado interno e, assim, poder usá-lo como combustível para os motores das locomotivas, que movimentavam a malha ferroviária do País na época. No entanto, com a estabilização do mercado internacional do petróleo, após o término da Segunda Guerra Mundial, esses esforços foram abandonados até o início da década de 1970, quando ocorreu uma nova crise de abastecimento, originada pela criação da OPEP. Em resposta a esta nova crise, foi criado pelo governo federal, além do Pró-Álcool, o Plano de Produção de Óleos Vegetais para Fins Energéticos, o PróÓleo. Este programa tinha como objetivo gerar um excedente de óleos vegetais, capaz de tornar seus custos de produção competitivos com os do óleo mineral. Previa-se uma regulamentação de uma mistura de 30\% de óleo vegetal no óleo diesel, havendo perspectivas para sua substituição integral em longo prazo. Nesta época foi proposta como alternativa tecnológica a transesterificação ou alcoólise de óleos vegetais, produzindo o biodiesel. O programa foi abandonado pelo governo em 1986, quando o preço do petróleo voltou a cair no mercado internacional (GUERRA; FUCHS, 2009a; FUCHS, 2007).

Em função do interesse em se descobrir alternativas ao uso do petróleo, vários ministérios, institutos de pesquisa e universidades se uniram para tornar possível o uso de óleo vegetal e seus derivados como alternativa ao diesel fóssil. Dentre as alternativas destacam-se o uso direto do óleo vegetal (puro ou em misturas com diesel de petróleo) e o uso de hidrocarbonetos obtidos pela sua quebra termocatalítica.

Foi instalado em 1983 o Programa de Óleos Vegetais (OVEG), que teve contribuição significativa para a aplicação de óleos vegetais em veículos. Os veículos da frota testados rodaram mais de 1 milhão de $\mathrm{km}$ na época. Na Universidade Federal do Ceará foram iniciadas pesquisas com biodiesel em 1970, o Prodiesel, a partir de óleos vegetais, e em 1982, com querosene vegetal para aviões a jato, o Prosene, aprovado e homologado pelo Centro Tecnológico Aeroespacial Brasileiro (CTA). Os trabalhos foram interrompidos por várias razões, incluindo a redução no preço do petróleo. Em 2002, após nova crise do petróleo, aliada ao conceito de desenvolvimento sustentável e por pressão de agências ambientais ao setor automotivo, foi criado o Programa de Desenvolvimento Tecnológico de Biodiesel Brasileiro (Probiodiesel), pelo Ministério da Ciência e Tecnologia (SOCCOL etal., 2005).

Em 2008, foi aprovado no senado o Projeto de Lei n. 81/2008, do senador Gilberto Goellner, que autoriza a comercialização do óleo vegetal in natura como combustível e a sua utilização em maquinário agrícola, bem como no transporte rodoviário, ferroviário ou hidroviário da produção agrícola e de seus insumos.

Rev. Acad., Ciênc. Agrár. Ambient., Curitiba, v. 8, n. 1, p. 103-112, jan./mar. 2010 
A companhia aérea TAM anunciou que fará, no segundo semestre de 2010, o primeiro voo da América Latina com bioquerosene de aviação produzido com óleo de pinhão-manso, uma planta brasileira. A aeronave utilizada será um Airbus A320. Um dos benefícios esperados do combustível na área de sustentabilidade é que o bioquerosene de pinhão-manso emite entre $65 \%$ e $80 \%$ menos carbono que o querosene atualmente usado nas aeronaves, derivado de petróleo. Porém, a cadeia de produção do bioquerosene não está formada no Brasil, estimando-se que haja cerca de 60 mil hectares de área plantada de pinhão-manso no país, com capacidade de produzir 1,5 toneladas de óleo/ha. A previsão é que no voo teste sejam utilizadas nove toneladas do bioquerosene, com $50 \%$ do óleo de pinhão-manso e $50 \%$ de querosene convencional.

A companhia aérea japonesa Japan Airlines (JAL) realiza testes com biocombustíveis em aviões desde janeiro de 2009, quando, num voo experimental com um Boeing 747-300, sem passageiros ou carga, um dos quatro reatores foi alimentado com uma mistura de biocombustível de "segunda geração", processado a partir de três tipos de plantas não alimentares. Foi utilizada uma mistura de $50 \%$ de querosene e $50 \%$ de biocombustível, com $84 \%$ de camelina, menos de $16 \%$ de pinhão manso e $1 \%$ de algas.

Algumas experiências com biocombustíveis se destacam, como a do engenheiro químico Hernani de Sá, que foi o pioneiro em biocombustíveis no Brasil, em especial com óleos vegetais. No fim da década de 1970, ele demonstrou o uso de óleo de dendê, soja e amendoim em motores. Há também o experimento do Instituto Agronômico de Campinas (IAC), que testou o funcionamento de um motor da MWM com óleo puro de girassol. Outras experiências importantes são a de Thomas Fendel, que usou um veículo Toyota abastecido com 93\% de óleo vegetal e 7\% de álcool, e a de Paulo Lehnhardt, que usou uma caminhonete S10 movida a óleo de fritura, no Rio Grande do Sul, tendo já adaptado diversos veículos para 100\% de óleo vegetal de fritura, entre tratores, barcos e caminhões (GUERRA; FUCHS, 2009b; FUCHS, 2006).

No Projeto das Mini-Usinas Comunitárias de Óleo Vegetal, no Estado do Paraná, foi aplicado óleo vegetal extraído a frio e microfiltrado a 0,5 micra em uma caminhonete Toyota Hylux. Esse veículo tem sistema de injeção eletrônica commom rail, com $20 \%$ de óleo de soja, girassol e canola em mistura com óleo diesel (na Alemanha, a filtragem é inferior a 4,0 micras, menos rigoroso que em nosso sistema). Apresentou ótimos resultados, avaliada periodicamente de 2007 a 2009, até os 76 mil km, pela própria agência concessionária (leituras de injeção) e pelo Instituto Tecnológico do Paraná (TECPAR). O óleo vegetal também foi aplicado em tratores (diversos percentuais de mistura sem alteração do motor) e em uma camionete S10 usada, com adaptação no motor para uso de 100\% de óleo vegetal, na Cooperativa Witmarsum, município de Palmeira, Paraná. Está em andamento no Centro Paranaense de Agroecologia (CPRA), em Pinhais, PR, o teste de $20 \%$ de óleo vegetal em trator CNH, já com 600 horas avaliadas pela empresa fabricante e pelo TECPAR. O objetivo desse projeto foi inserir a produção e o consumo de óleo vegetal na cadeia produtiva diversificada do agricultor (GUERRA; FUCHS, 2009a).

\section{Tipos de biocombustíveis}

Os combustíveis biológicos usados atualmente envolvem diferentes técnicas de produção e processamento, destacando-se o biodiesel, o álcool, o biogás e o óleo vegetal (GUERRA; FUCHS, 2009a). O biodiesel é usado nos motores a diesel tradicionais, sem necessidade de adaptações; o álcool combustível, em motores adaptados; e o biogás, para geração de energia térmica, elétrica ou mecânica, em motores apropriados ou adaptados.

O óleo vegetal, em estado natural, é menos conhecido como combustível para motores, mas seu uso está se intensificando nos motores a diesel, desenvolvidos ou convertidos para esse fim. É difícil estimar a quantidade usada extraoficialmente em misturas em frotas de empresas, principalmente no maquinário agrícola.

Ao contrário da gasolina e do diesel obtido do petróleo, o óleo vegetal é regenerativo, neutro quanto à emissão de $\mathrm{CO}_{2}$ e livre de enxofre, metais pesados e radioatividade. Além disso, não é finito como os derivados de petróleo, podendo ser produzido em vários países e sob as mais variadas condições climáticas. É um combustível seguro e de baixo custo. O óleo vegetal não é volátil e tem um ponto de fulgor em torno de $200^{\circ} \mathrm{C}$, de modo que não é inflamável e nem explosivo, podendo ser armazenado sem riscos por longos períodos. Também é biodegradável, não prejudicando nem a terra, nem o ar, nem a água.

Rev. Acad., Ciênc. Agrár. Ambient., Curitiba, v. 8, n. 1, p. 103-112, jan./mar. 2010 
No caso mais simples, os óleos vegetais são obtidos pelo esmagamento dos grãos e pela subsequente prensagem a frio, sendo que os materiais suspensos são separados do óleo natural pela sedimentação e posterior filtragem. Na Tabela 1 apresenta-se a estimativa do teor de óleo vegetal de algumas espécies cultivadas.

Tabela 1 - Estimativa de teor de óleo de algumas espécies oleaginosas

\begin{tabular}{llll}
\hline Espécie & Teor de óleo (\%) & Espécie & Teor de óleo (\%) \\
\hline Amendoim & $40-50$ & Girassol & $35-52$ \\
Algodão & $15-25$ & Linhaça & $30-48$ \\
Babaçu & $55-65$ & Mamona & $40-50$ \\
Canola & $40-50$ & Nabo forrageiro & $35-50$ \\
Cártamo & 35 & Soja & $18-22$ \\
Dendê & $45-50$ & Tungue & $30-35$ \\
Gergelim & $50-55$ & Pinhão-manso & $38-45$ \\
\hline
\end{tabular}

Fonte: Adaptado de GUERRA; FUCHS, 2009.

$\mathrm{Na}$ Tabela 2 são apresentadas, de maneira comparativa, as características físicas e químicas de óleo vegetal de canola e biodiesel. Uma revisão sobre as características avaliadas pode ser encontrada em Furlan (2006), em que também se observam os dados coletados de babaçu, dendê (polpa), amendoim e soja comparados com o diesel.

Tabela 2 - Algumas características físicas e químicas de óleo vegetal combustível e biodiesel

\begin{tabular}{|c|c|c|c|}
\hline & $\begin{array}{l}\text { Óleo vegetal } \\
\text { Matéria-prima natural não- } \\
\text { modificada }\end{array}$ & $\begin{array}{l}\text { Biodiesel } \\
\text { Derivado esterificado } \\
\text { de óleo vegetal }\end{array}$ & Unidade \\
\hline \multicolumn{4}{|l|}{ Características físicas } \\
\hline Densidade & $0,90-0,92$ & 0,88 & $\mathrm{Kg} / \mathrm{L} ; 20{ }^{\circ} \mathrm{C}$ \\
\hline Viscosidade cinemática & $60-80$ & $7-8$ & $\mathrm{~mm}^{2} / \mathrm{s} ; 20^{\circ} \mathrm{C}$ \\
\hline Ponto de ignição & $>220$ & 135 & ${ }^{\circ} \mathrm{C}$ \\
\hline Ponto de congelamento & -8 a -18 & -12 & ${ }^{\circ} \mathrm{C}$ \\
\hline \multicolumn{4}{|l|}{ Características químicas } \\
\hline Teor de fósforo & $<15$ & $<15$ & $\mathrm{mg} / \mathrm{kg}$ \\
\hline Teor de enxofre & $<10$ & $<100$ & $\mathrm{mg} / \mathrm{kg}$ \\
\hline Comportamento químico & lento para reações e neutro & $\begin{array}{l}\text { de fácil reação, solvente, } \\
\text { higroscópico }\end{array}$ & \\
\hline Densidade energética & 9,2 & 8,9 & $\mathrm{KWh} / 1$ \\
\hline
\end{tabular}

Fonte: SCHRIMPFF, 2002b. 
Sob a perspectiva motora, as características físicas da viscosidade cinemática e do ponto de ignição depõem em favor do biodiesel, porque se aproximam consideravelmente mais das propriedades do diesel mineral do que os óleos vegetais. Os óleos vegetais e o biodiesel apresentam propriedades químicas que precisam ser classificadas como significativamente mais favoráveis em comparação com o diesel, que leva a uma menor emissão de gases (SCHRIMPFF, 2002b). Para reduzir a alta viscosidade dos óleos vegetais, a solução é instalar um sistema de preaquecimento, posicionado antes da bomba injetora.

Considerando que, ao contrário dos óleos vegetais, o biodiesel age como um solvente, causando problemas com mangueiras e juntas do motor, além de ser bastante higroscópico (absorve água e dilui óleos do motor, levando à necessidade de duas vezes mais trocas de óleo e filtros que nos motores a diesel ou óleo vegetal), observa-se uma nítida vantagem para os óleos vegetais. Além disso, os óleos possuem propriedades lubrificantes consideravelmente melhores. Na densidade energética, os óleos vegetais e o biodiesel apresentam pouca diferença, situando-se como combustíveis entre a gasolina e o diesel (SCHRIMPFF, 2002a). No entanto, diferenças marcantes podem ser constatadas na obtenção dos dois combustíveis. As diferenças dizem respeito ao princípio de produção: para óleo vegetal, é possível estabelecer numerosas pequenas usinas de óleo descentralizadas, ao passo que, para o biodiesel, são necessárias predominantemente poucas usinas centrais de grande porte. Também há diferenças no dispêndio de trabalho (são três passos básicos para a produção do óleo vegetal e oito para o biodiesel) e de energia.

Os principais passos para a produção de óleo vegetal e as questões do transporte, da armazenagem e da tolerância ambiental e social são apresentados nas Tabelas 3 e 4.

Tabela 3 - Dispêndio de trabalho e energia para obtenção dos óleos vegetais e do biodiesel

\begin{tabular}{|c|c|c|c|c|}
\hline \multirow[t]{9}{*}{ Dispêndio de trabalho } & \multicolumn{2}{|c|}{ Óleos vegetais } & \multicolumn{2}{|r|}{ Biodiesel } \\
\hline & a) & limpeza dos grãos & a) & limpeza dos grãos \\
\hline & b) & prensagem a frio & b) & prensagem a frio \\
\hline & c) & filtragem do óleo natural & c) & filtragem do óleo natural \\
\hline & & - & d) & extração (hexano) \\
\hline & & - & e) & destilação (hexano) \\
\hline & & - & f) & extração da goma \\
\hline & & - & g) & refino do óleo \\
\hline & & - & h) & esterificação \\
\hline
\end{tabular}

\section{Dispêndio de energia}

Cultivo de oleaginosas

$12 \%$

$12 \%$

Extração do óleo

$3 \%$

$7 \%$

Esterificação

$17 \%$

Crédito de glicerina

$-4 \%$

Total

$15 \%$

$32 \%$

Fonte: SCHRIMPFF, 2002b.

Para a produção do óleo vegetal são consumidos 15\% do teor energético do próprio óleo vegetal, enquanto que para o biodiesel são necessários 36\% do seu próprio teor energético. O biodiesel possui um crédito energético pelo subproduto obtido, a glicerina, que pode ser calculado em 4\%, de modo que o total de gasto energético na produção de biodiesel cai para 32\%. Entretanto, o processo de transesterificação também gera perdas, ao passo que o OV é aproveitado integralmente na combustão. 
Tabela 4 - Riscos na armazenagem e no transporte, tolerância ambiental e social dos combustíveis

\begin{tabular}{lll}
\hline & Óleos vegetais & Biodiesel \\
\hline Armazenagem e transporte & Totalmente sem problemas & $\begin{array}{l}\text { Risco maior } \\
\text { Facilmente inflamável } \\
\end{array}$ \\
Tolerância ambiental: & & Menor tolerância ambiental \\
Decomposição biológica & Muito rápida & Retardada \\
Risco para a água & Nenhum (nível 0) & Baixo (nível 1) \\
Toxicidade para humanos & Via de regra não-tóxico, & Não comestível, graças \\
Ciclos de matéria orgânica & bom óleo comestível & à esterificação, tóxico \\
\hline Tolerância social: & Fácil de fechar & Viável a custos elevados \\
Estratégia & & \\
Logística & Descentralizada, pequena & Centralizada, grande \\
Rotas de transporte & Simples & Mais complexa \\
Vulnerabilidade & Curtas & Mais longas \\
Agregação de valor regional & Baixa & Maior \\
\hline
\end{tabular}

Fonte: SCHRIMPFF, 2002b.

O transporte e a armazenagem de ambos os combustíveis são nitidamente menos problemáticos que no caso do diesel. Mas no biodiesel há um risco maior que nos óleos vegetais, pois pode se incendiar com maior facilidade e é menos tolerado pelo meio ambiente.

\section{Exemplo de uso de óleo vegetal em motores}

Em novembro de 2004 foi celebrado convênio de cooperação técnica e financeira do Instituto Cristão de Desenvolvimento (ICD) com o governo do Estado do Paraná, representado pelo TECPAR, para instalação de uma usina-modelo de extração de óleo vegetal a frio. O projeto em parceria com a Cooperativa Witmarsum, em Palmeira, PR, também recebeu apoio financeiro do Ministério do Desenvolvimento Agrário. A capacidade de esmagamento é de $150 \mathrm{~kg} / \mathrm{h}$, podendo ser ampliado com o acréscimo de mais prensas em série (GUERRA; FUCHS, 2009b).

Desde o início previa-se no projeto o teste de óleos vegetais em motores, visando à verificação de consumo, desempenho, adaptação da injeção eletrônica e características do óleo do cárter. Assim, o óleo vegetal produzido em Witmarsum vem sendo usado em tratores (em diversos percentuais de mistura, sem alteração do motor) e em uma caminhonete S10 usada, adaptada para uso de 100\% de óleo vegetal.

Foi adquirida por parte do governo do Estado do Paraná, para testes com óleo vegetal, uma caminhonete de última geração com sistema de injeção eletrônica common rail. A opção pela marca e modelo deveu-se às características já presentes no motor Elko (pistões e câmaras de combustão), desenvolvido especificamente para óleos vegetais nos anos 80, na Alemanha. Entre 2007 e 2009 o veículo foi usado em testes com óleo produzido numa miniusina compacta de extração a frio.

Foi utilizada na caminhonete, inicialmente, a mistura de diesel com $20 \%$ de óleo de soja extraído por prensagem a frio e filtrado a 0,5 micron, produzido pela Miniusina de Witmarsum. A opção pela prensagem 
a frio, abaixo de $45^{\circ} \mathrm{C}$, deve-se a comprovadas vantagens técnicas sobre o óleo extraído a quente: baixos teores de goma $(0,5 \%$, enquanto a extração a quente chega a $12 \%)$ e, consequentemente, baixos teores de substâncias nocivas ao funcionamento do motor (fósforo, cálcio e magnésio). Cumpre destacar que a norma alemã DIN 51605/2006 para colza estabelece os limites máximos dos teores de cálcio e magnésio em 20 $\mathrm{mg} / \mathrm{kg}$, e de fósforo em $12 \mathrm{mg} / \mathrm{kg}$. Em vista dos altos teores observados na extração a quente (128, 91 e 525 $\mathrm{mg} / \mathrm{kg}$ de fósforo, cálcio e magnésio, respectivamente), mesmo com boa filtragem, o óleo extraído a quente deixará depósitos em bicos injetores e câmaras de combustão e ainda causará corrosão, comprometendo a durabilidade do motor e de outros componentes. O óleo extraído a quente necessita de refino industrial para assegurar a redução eficiente desses teores e com custo elevado no processo. Diferentemente disso, o óleo vegetal extraído a frio e filtrado a 0,5 micron assegura uma injeção de qualidade, considerando uma bomba injetora de combustível para 1,0 micron (GUERRA; FUCHS, 2009b).

O motor foi amaciado com diesel comum (ou biodiesel), encontrado normalmente nos postos. Após $10 \mathrm{mil} \mathrm{km}$, foi feita a primeira revisão. O consumo foi aferido mais duas vezes e escaneada e impressa toda a eletrônica do veículo pela agência Toyota. A partir dos $12.188 \mathrm{~km}$ passaram a ser adicionados ao tanque $20 \%$ de óleo de soja. Aos 20 mil km foi efetuada a segunda revisão de rotina na agência e coletado o óleo de cárter para análise. Não foi possível fotografar o estado dos bicos injetores, porque a agência local não possuía o kit de reposição da vedação, pois nem sequer há previsão dessa verificação pela fábrica. No entanto, não foi adicionado o aditivo recomendado para limpeza de bicos injetores e câmaras de combustão (PARANÁ, 2006; ICD, 2007; PARANÁ, 2008; ICD, 2008).

A média geral de consumo dos 12 mil km percorridos apenas com diesel foi de $12,26 \mathrm{~km} / \mathrm{L}$. A média dos 8,7 mil km rodados com mistura OV20 (20\% de óleo vegetal) foi de 12,22 km/L. Ou seja, não houve alteração do consumo. A média no fim das avaliações, com $76 \mathrm{mil} \mathrm{km}$, foi de 11,72 km/L (PARANÁ, 2006; ICD, 2007; PARANÁ, 2008; ICD, 2008).

Também não foram observadas mudanças no desempenho, na avaliação subjetiva dos que dirigiram o veículo. $\mathrm{O}$ indicador de temperatura permaneceu na mesma posição com ambos os combustíveis.

Foi realizada a segunda leitura da eletrônica, para verificar se os sensores detectaram a mistura e se efetuaram adequação da injeção, o que foi confirmado com a pressão do combustível na injeção mantendose constante.

Esse resultado da "resposta" da injeção eletrônica é altamente positivo. O teste, inédito no contexto brasileiro em termos de injeção eletrônica, permite concluir preliminarmente que a mistura de $20 \%$ desse combustível ecológico é viável em veículos desse tipo. Em motores comuns é possível misturar 40\% ou mais de óleo vegetal extraído a frio, sem alterações no motor, dependendo da capacidade da bomba injetora. Porém, para misturas maiores ou para uso de OV100, é preciso pré-aquecer o óleo a $70^{\circ} \mathrm{C} \mathrm{em} \mathrm{motores} \mathrm{comuns.} \mathrm{No}$ sistema de injeção common rail (com 1.500 bar de pressão), esse pré-aquecimento é dispensável, mas será preciso programar a eletrônica em "sintonia fina" com as características de cada óleo vegetal (soja, nabo forrageiro, pinhão manso, etc.) (GUERRA; FUCHS, 2009b).

\section{Índices de qualidade de óleo vegetal combustível}

A venda de óleo virgem comestível e medicinal certamente assegura ganhos maiores que seu uso como combustível. Por isso, recomenda-se usar o óleo vegetal como combustível apenas em segundo lugar. No entanto, existem oleaginosas não comestíveis, como pinhão-manso, crambe, nabo forrageiro, tungue e outros, cujo óleo pode ser extraído na entressafra de outras culturas e empregado como excelente combustível. Além disso, com baixo custo de produção, qualquer óleo vegetal se torna vantajoso em relação ao diesel e chega a ser $40 \%$ mais barato que o biodiesel, motivo pelo qual já existe na Europa grande quantidade de veículos movidos a óleo vegetal, principalmente de canola.

O óleo vegetal tem em seu favor o fato de ser um combustível renovável e abundante, não finito como os derivados de petróleo. Pode ser produzido sob as mais variadas condições climáticas, em todos os países. É um combustível seguro e de baixo custo. Ao ser queimado, apenas devolve à atmosfera uma parte do carbono que a planta fixou pela fotossíntese (por isso se diz que é neutro em termos de $\mathrm{CO}_{2}$ ).

Rev. Acad., Ciênc. Agrár. Ambient., Curitiba, v. 8, n. 1, p. 103-112, jan./mar. 2010 
O óleo vegetal não é volátil e tem um ponto de fulgor em torno de $220^{\circ} \mathrm{C}$, de modo que não é inflamável nem explosivo, e pode ser armazenado sem riscos por longos períodos. Também é biodegradável, não prejudicando a terra, nem o ar, nem a água.

A Tabela 5 apresenta algumas características dos óleos vegetais em comparação com o diesel e o biodiesel.

Tabela 5 - Características dos óleos vegetais comparadas com o diesel e o biodiesel

\begin{tabular}{lrrrrr}
\hline & $\begin{array}{c}\text { Óleo de } \\
\text { canola }\end{array}$ & $\begin{array}{c}\text { Óleo de } \\
\text { pinhão-manso }\end{array}$ & $\begin{array}{c}\text { Óleo de } \\
\text { soja }\end{array}$ & Diesel & Biodiesel \\
\hline Densidade $\left(\mathbf{g} / \mathbf{c m}^{\mathbf{3}}\right)$ & $0,91-0,93$ & $0,91-0,92$ & - & $0,82-0,85$ & $0,86-0,90$ \\
Viscosidade a $\mathbf{4 0}^{\circ}\left(\mathbf{m m}^{2} \mathbf{s}\right)$ & 38 & - & 36,8 & $2-4,5$ & $3,5-5,0$ \\
$\begin{array}{l}\text { Facilidade de ignição } \\
\text { (índice de cetanas) }\end{array}$ & $40-42$ & 51 & $36-39$ & $51-56$ & 50 \\
Valor calorífico $(\mathbf{K j} / \mathbf{K g})$ & 35.000 & $39.500-41.700$ & 39.950 & $41.400-43.500$ & 36.200 \\
Ponto de fulgor $\left({ }^{\circ} \mathbf{C}\right)$ & 220 & $110-240$ & - & $50-80$ & $120-135$ \\
Teor de fósforo $(\mathbf{\%})$ & 12 & - & 5 & - & - \\
\hline \hline
\end{tabular}

É possível misturarao diesel de 15\% a 50\% deóleo vegetal, sem adaptaçãono motora diesel, dependendo do tipo (injeção direta ou indireta, turbo, eletrônica, etc.). É importante ter cuidado com o óleo do cárter e verificar regularmente os bicos injetores. Graças à maior lubricidade, o desempenho dos motores movidos a óleo vegetal é equivalente aos movidos a diesel e um pouco melhor que por biodiesel. Contudo, o óleo vegetal requer rigorosa padronização e controle de qualidade, conseguidos principalmente pela extração a frio e pela microfiltragem. A referência é a norma alemã DIN 51605, desenvolvida basicamente para qualificar o óleo de canola. Ainda não há uma norma feita no Brasil, mas notícias recentes informam que o Inmetro está trabalhando em uma padronização.

\section{Considerações finais}

O uso de óleo vegetal em motores é uma alternativa viável e vantajosa, tanto pelo balanço energético e custo menor, quanto pelo seu aproveitamento integral, sem as perdas que ocorrem no craqueamento e na transesterificação. Observando-se o conceito de desenvolvimento sustentável, sua produção e aproveitamento apresentam vantagens ambientais. Mas, por falta de uma política oficial favorável e contínua no Brasil, os testes com óleo vegetal em motores são fragmentados e pouco sistematizados, distribuídos pelo país em iniciativas isoladas de indivíduos e alguns poucos institutos, como a Coordenadoria de Assistência Técnica Integral (CATI) e o TECPAR.

Novos experimentos com óleo vegetal como biocombustível devem ser instalados, com vistas a: analisar as diferentes propostas de filtração do óleo e de adaptação de motores, com kits nacionais e importados de países como a Alemanha, em que os invernos são mais rigorosos; separar claramente entre motores convencionais e de injeção eletrônica, uma vez que o teste bem-sucedido com a Toyota - Hilux, com $20 \%$ de óleo vegetal sem alterações no motor, por enquanto é o único de que se tem conhecimento no País realizado com injeção eletrônica, e faltaria um teste com adaptação da injeção eletrônica para 100\% de OV direto; avaliar o grau de autossustentabilidade local e a facilidade de adaptação e manutenção do motor, por exemplo, dos pescadores com barcos movidos a óleo de fritura e ribeirinhos na Amazônia, utilizando OV de diversas oleaginosas nas embarcações.

Considerando que o uso do biodiesel está se definido como aditivo ao diesel e não como substituto, na Europa as misturas ao diesel prevalecem sobre o uso do B100 e não requerem uma estrutura e logística próprias de distribuição, razão pela qual o óleo vegetal preenche a função de aditivar o diesel ou de ser misturado a ele em proporções maiores. 


\section{Referências}

FUCHS, W. Colha óleo vegetal. Curitiba: ICD/REPAS, 2006. 120 p.

. Entregar os dedos para não perder os anéis? Biocombustíveis e sustentabilidade. Cotton Business, n. 5, 2007. Disponível em: <http://www.algodao.agr.br/zip/art_revista25.pdf>. Acesso em: 18 out. 2009.

. Terra que emana azeite e mel. Revista da Madeira, v. 19, n. 115, p. 78-79, 2008.

O lavrador que trabalha deve ser o primeiro a participar dos frutos. In: UCZAI, P. (Org.). Inevitável mundo novo: relação entre energias renováveis, produção de alimentos e o futuro do planeta. Chapecó: Palotti, 2009. p. 364.

FURLAN, J. J. et al. Biodiesel: porque tem que ser dendê. Belém: Embrapa Amazônia Oriental; Palmasa, 2006.

GUERRA, E. P.; FUCHS, W. Mini-usina de óleo vegetal comestível e biocombustível. In: SIMPÓSIO BRASILALEMANHA/ DEUTSCH-BRASILIANISCHES SYMPOSIUM, 4., 2009, Curitiba. Anais... Curitiba: UFPR, 2009a. CD-ROOM.

GUERRA, E. P.; FUCHS, W. Produção de óleo vegetal: comestível e biocombustível. Viçosa: CPT, 2009 b. $226 \mathrm{p}$.

INSTITUTO CRISTÃO DE DESENVOLVIMENTO - ICD. Óleo vegetal direto em caminhonete de injeção eletrônica Toyota nova Hilux. Curitiba: ICD/REPAS. 2007. 7 p. Relatório parcial n. 1.

INSTITUTO CRISTÃO DE DESENVOLVIMENTO - ICD. Óleo vegetal direto em caminhonete de injeção eletrônica Toyota nova Hilux. Curitiba: ICD/REPAS. 2008. 25 p. Relatório parcial n. 2.

MELO, J. A. S. de. Inovação tecnológica: o uso direto de óleos vegetais como vetor energético no Brasil. 2009. 127 f. Dissertação (Mestrado em Desenvolvimento Sustentável) - Universidade de Brasília, Brasília, 2009.

PARANÁ. Instituto de Tecnologia do Paraná: divisão de Biocombustíveis. Curitiba: TECPAR, 2006. Relatório de ensaio, 06010909.

Instituto de Tecnologia do Paraná: divisão de Biocombustíveis. Curitiba: TECPAR, 2008. Relatório de ensaio - DB - 077/08.

SCHRIMPFF, E. A posição do óleo vegetal: comparado a outros combustíveis de origem biológica. Alemanha, 2002a. Disponível em: <http://www.projetobr.com.br/c/document_library/get_file?folderId=75\&name= \%C3\%93leo+Vegetal+2+-+Prof.+Schrimpff.pdf\&download=true.>. Acesso em: 5 dez. 2008.

Biodiesel ou óleo vegetal: a pergunta pela melhor estratégia de combustíveis. Alemanha, 2002b. Disponível em: <http://www.projetobr.com.br/c/document_library/get_file?folderId $=75$ \&name=Vegetal++ Prof+1+.+Schrimpf.pdf\&download=true $>$. Acesso em: 5 dez. 2008.

SOCCOL, C. R. et al. Brazilian biofuel program: an overview. Journal of Scientific and Industrial Research, v. 64, p. 897-904, 2005.

Recebido: 20/11/2009

Received: $11 / 20 / 2009$

Aprovado: 22/12/2009

Approved: 12/22/2009

Rev. Acad., Ciênc. Agrár. Ambient., Curitiba, v. 8, n. 1, p. 103-112, jan./mar. 2010 